\title{
Role of serum progesterone in threatened miscarriage
}

\author{
Anupama Dave, Ranjana Patil, Priya Bansal, Anjali Malhotra*
}

Department of Obstetrics and Gynecology, MGMMC and MYH, Indore, Madhya Pradesh, India

Received: 04 April 2018

Revised: 21 August 2018

Accepted: 28 August 2018

\section{* Correspondence:}

Dr. Anjali Malhotra,

E-mail: anjalimalhotra.mbbs@gmail.com

Copyright: () the author(s), publisher and licensee Medip Academy. This is an open-access article distributed under the terms of the Creative Commons Attribution Non-Commercial License, which permits unrestricted non-commercial use, distribution, and reproduction in any medium, provided the original work is properly cited.

\section{ABSTRACT}

Background: Miscarriage is the inadvertent loss of a pregnancy before the fetus is viable. The World Health Organization defines this un-survivable state as an embryo or fetus weighing 500 grams or less, which typically corresponds to a fetal age (gestational age) of 20 to 22 weeks or less.

Methods: The present study was conducted in the Department of Obstetrics and Gynaecology, M. G. M. Medical College and M.Y. Hospital, Indore from October 2013 to October 2014 on 100 patients.

Results: The incidence of first trimester threatened miscarriage, in the Gynaec O.P.D. of M.Y. Hospital, Indore, was $8.8 \%$. The most common risk factor was a history of previous miscarriages in $38 \%$ of cases while $9 \%$ had advanced maternal age and $35 \%$ had advanced paternal age. History of preterm labour was positive in $25 \%$ cases and that of congenital anomaly in previous pregnancy in $7 \%$ cases. UTI and vaginitis were diagnosed in $10 \%$ and $11 \%$ cases respectively. Systemic illness was in $24 \%$ cases while $6 \%$ cases had endocrine disorders. On USG missed miscarriage was found in $8 \%$ inconclusive ultrasound was found in $34 \%$ cases, rest were normal. Of the 38 cases giving history of previous 1, 2, 3 and more than or equal to 4 miscarriages were $22 \%, 6 \%, 8 \%$ and $2 \%$ respectively. $36 \%$ of the patients presented with bleeding per vaginum. only while $30 \%$ had bleeding with pain and $33 \%$ cases had only pain in abdomen. On USG 58\% had normal scans. USG scan was inconclusive in 34\% and only 35\% continued with viable pregnancy, rest aborted. 7 of the 100 cases had preterm labour and 51 cases continued to term. Rest 42 aborted. H/o contact, travel, trauma, heavy work did not have any statistically proven effect on outcome of pregnancy.

Conclusions: Progesterone assays are currently available in most immunoassay platforms and have shown excellent performance in terms of assay sensitivity, specificity, accuracy and precision with rapid turnaround times. Furthermore, the cost per test for progesterone assay is affordable. Several studies have shown that progesterone is the most specific biomarker for distinguishing viable from nonviable pregnancies. The downfall of progesterone as a biomarker is due to the different cut-off values used by researchers. The cut-off values were also determined on different study populations.

Keywords: Miscarriage, Preterm labour, USG, UTI, Vaginum

\section{INTRODUCTION}

Threatened miscarriage is very common in the first trimester; about $25-30 \%$ of all pregnancies have some bleeding during the pregnancy. ${ }^{1,2} 12 \%$ to $20 \%$ of all clinically recognized pregnancies end up as miscarriages. $^{3,4}$ On examination, blood or brownish discharge may be present in the vagina. The cervix is not tender, and the cervical os is closed. No foetal tissue or membranes have passed. The ultrasound shows a continuing intrauterine pregnancy. If an ultrasound was not performed previously, it is required at this time to rule out an ectopic pregnancy, which could present similarly. Ultrasound scanning is probably the best single 
diagnostic and prognostic test available for diagnosing early pregnancy failure. However, there were certain conditions where both the ultrasonographic evidence and clinical findings were indeterminate. ${ }^{5}$ In addition, this technique is dependent upon the skill of the operator and thus the results are not always consistently reproducible. Therefore, a highly sensitive and specific biomarker is required to determine the pregnancy viability for early intervention.

Progesterone is a C-21 steroid hormone secreted by granulosa cells of the ovary. This hormone is important to promote endometrial decidualization by preparing the uterus for implantation of the blastocyst and in maintaining the pregnancy. ${ }^{6,7}$ The downfall of progesterone as a biomarker is due to the different cut-off values used by researchers., ${ }^{7,9-11}$ The cut-off values were also determined on different study populations. Other important physiological function of progesterone is to inhibit smooth muscle contractility, decrease prostaglandin formation which help maintain myometrial quiescence and prevent the onset of uterine contractions, and inhibit immune responses like those involved in graft rejection. $^{12}$

Progesterone assays are currently available in most immunoassay platforms and have shown excellent performance in terms of assay sensitivity, specificity, accuracy and precision with rapid turnaround times. Furthermore, the cost per test for progesterone assay is affordable. Several studies have shown that progesterone is the most specific biomarker for distinguishing viable from nonviable pregnancies. ${ }^{7,8,13,14}$

The aims and objectives are to study the incidence of threatened miscarriage; to study the various etiological factors functional in patients of threatened miscarriage and to study the pregnancy outcome and role of USG and chief complaints in these patients and to study the role of single serum progesterone assay and determine the cut off level of serum progesterone in detecting the viability of pregnancy.

\section{METHODS}

The present study was conducted in the Department of Obstetrics and Gynaecology, M. G. M. Medical College and M.Y. Hospital, Indore. The period of study was October 2013 to October 2014. The study was conducted on 100 patients. These patients were selected from all age groups, parity, socioeconomic and educational status from the patients attending Gynae OPD, presenting in first trimester of pregnancy.

\section{Inclusion criteria}

- Attending gynae OPD during the period

- In first trimester of pregnancy $<12$ weeks

- Chief complaints of bleeding P/V, Lower abdomen pain or both
- $\quad$ UPT positive

- Cervix-closed os.

\section{Exclusion criteria}

- Multifetal gestation

- Ectopic pregnancy

- $\quad$ ART Induced pregnancy.

\section{Methodology}

Detailed history of patient was taken. During history taking special importance was given to few salient features.

- Previous obstetric history and prior pregnancy losses and Menstrual history.

- History of any risk factors contributing to threatened miscarriages or any systemic diseases and medications during prenatal and antenatal period.

- Relevant Family history, especially regarding pregnancy losses in the family, any chromosomal or genetic disorder running in the family, or a history of diabetes, hypertension.

Physical examination was carried out with particular attention to:

- Obesity, hirsutism and acanthosis

- Breast and thyroid examination were conducted.

- A Per speculum examination was conducted. Status of os, any evidence of infection nature of bleeding or discharge per vaginum was noted.

\section{Investigations}

- Complete Blood count, RFT, LFT, ABO Rh, Urine Routine Microscopy, VDRL HIV, HbsAg, blood urea, and FBS, PPBS, GTT if required were carried out.

- All patients were subjected to sonography to confirm pregnancy and its location and viability and later for follow-up.

\section{Serum progesterone}

All cases undergo serum progesterone assay. Blood samples were collected immediately after admission and before initiation of treatment or surgical intervention. A maximum of $5 \mathrm{ml}$ venous blood was collected in a plain tube, centrifuged and the serum were aliquoted and stored at $-70^{\circ} \mathrm{C}$ until analysis was carried out.

Serum progesterone was measured on a fully automated analyzer (Architect i2000sr) using Chemiluminescent Microparticle Immunoassay (CMIA). The Architect progesterone assays measure progesterone concentrations between $0.1 \mathrm{ng} / \mathrm{ml}$ to $36.0 \mathrm{ng} / \mathrm{ml}$. All cases underwent 
USG and were under follow up till either Miscarriage or continued pregnancy.

\section{Statistical analysis}

The data was analyzed using Chi-square test and Fischer test (probability limit was 0.05). Serum progesterone levels were analysed by risk of curve analysis and cut-off value determined.

\section{RESULTS}

This table shows the incidence of first trimester threatened Miscarriage among cases attending Gynaec OPD. The incidence was $8.8 \%$.

Table 2 showing the maximum cases with pregnancy continued i.e. $61.3 \%$ and $56.7 \%$ cases in maternal age groups of 21-25 years and 26-30 years respectively.

Table 1: Incidence of threatened miscarriage.

\section{Parameters studied}

Total cases in $1^{\text {st }}$ trimester of pregnancy attending gynae O. P. D in study duration 1136

Total cases of threatened miscarriage attending gynae O. P. D in study duration 100

Incidence of $1^{\text {st }}$ trimester threatened miscarriage in gynae O. P. D

Table 2: Demographic profile.

\begin{tabular}{|c|c|c|c|c|c|}
\hline Maternal age (in years) & Frequency & Continued & Percentage & Aborted & Percentage \\
\hline$<20$ & 10 & 5 & 50 & 5 & 50 \\
\hline $21-25$ & 44 & 27 & 61.3 & 17 & 29.7 \\
\hline $26-30$ & 37 & 21 & 56.7 & 16 & 43.2 \\
\hline$>30$ & 9 & 5 & 55.5 & 4 & 44.4 \\
\hline Paternal age (in years) & Frequency & & & & \\
\hline$<20$ & 1 & 1 & 100 & 0 & 0 \\
\hline $21-25$ & 24 & 14 & 58.4 & 10 & 41.6 \\
\hline $26-30$ & 40 & 23 & 57.5 & 17 & 42.5 \\
\hline$>30$ & 35 & 20 & 57.1 & 15 & 42.8 \\
\hline Parity & Total cases & & & & \\
\hline Primiparity & 52 & 40 & 76.9 & 12 & 23.1 \\
\hline Multiparity & 38 & 18 & 47.3 & 20 & 52.6 \\
\hline
\end{tabular}

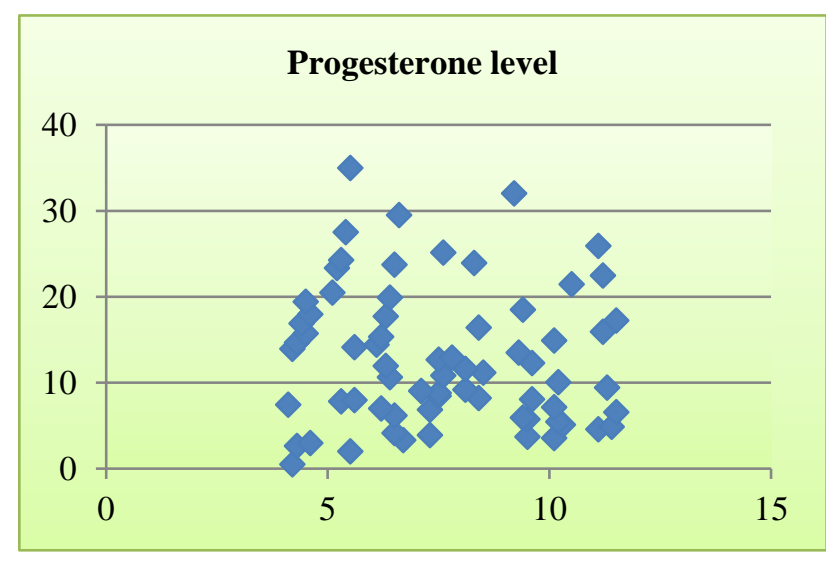

Figure 1: showing comparison of serum progesterone levels with respect to weeks of gestation with mean progesterone levels of $18.09 \mathrm{ng} / \mathrm{ml}$ for viable pregnancy.

However, in the paternal age groups 21-25, 26-30 and > 30 years pregnancy continued in 58.4, 57.5 and $57.1 \%$ cases respectively. The test result variable(s): serum progesterone has at least one tie between the positive actual state group and the negative actual state group. Statistics may be biased.

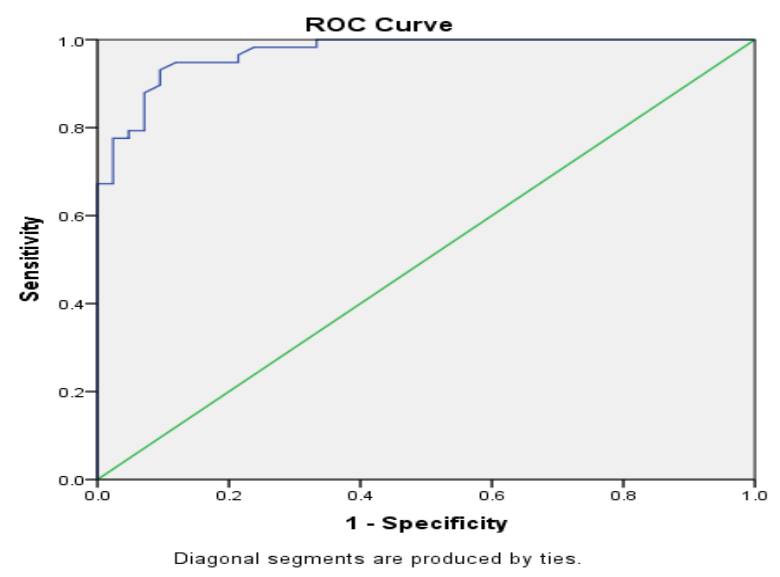

Figure 2: ROC curve for serum progesterone.

Under the nonparametric assumption, 
Null hypothesis: true area $=0.5$.

The smallest cut off value is the minimum observed test value minus 1 , and the largest cutoff value is the maximum observed test value plus 1 .

All the other cutoff values are the averages of two consecutive ordered observed test values. Cut off value with maximum sensitivity and specificity: 10.05 (sensitivity $93 \%$ and specificity $90.5 \%$ ).

Table 3: Serum progesterone.

\begin{tabular}{|lll|}
\hline Total cases & Viable & Non-viable \\
\hline 100 & 58 & 42 \\
\hline Mean progesterone levels (ng/ml) & 18.09 & 6.7 \\
\hline
\end{tabular}

The incidence of first trimester threatened Miscarriage, in the Gynae O.P.D. of M.Y. Hospital, Indore, was $8.8 \%$. There were 9 cases with maternal age $>30$ years. These cases showed a significantly higher Miscarriage rate of $44 \%$.

The study thus, proves that increased maternal age is a definite adverse factor in prognosis of threatened Miscarriage. The most common risk factor was a history of previous Miscarriages in $38 \%$ of cases.

Table 4: ROC curve and their relation to level of serum progesterone.

\begin{tabular}{|lllll|} 
Area & $\begin{array}{l}\text { Std. } \\
\text { error }\end{array}$ & $\begin{array}{l}\text { Asymptotic } \\
\text { sig. }\end{array}$ & $\begin{array}{l}\text { Asymptotic 95\% } \\
\text { confidence interval } \\
\text { Lower } \\
\text { bound }\end{array}$ & $\begin{array}{l}\text { Upper } \\
\text { bound }\end{array}$ \\
\hline 0.971 & 0.014 & 0.000 & 0.944 & 0.997 \\
\hline
\end{tabular}

The test result variable(s): serum progesterone has at least one tie between the positive actual state group and the negative actual state group. Statistics may be biased. a. Under the nonparametric assumption. $\mathrm{b}$. Null hypothesis: true area $=0.5$.

Advanced maternal age was seen in $9 \%$ of cases and advanced paternal age in $35 \%$. History of preterm labour was positive in $25 \%$ cases and that of congenital anomaly in previous pregnancy in $7 \%$ cases.

Table 5: Factors and the level of significance with respect to $p$-value.

\begin{tabular}{|ll|}
\hline Factors & P-value \\
\hline Maternal age & 0.539 (non-significant) \\
\hline Paternal age & 0.534 (non-significant) \\
\hline Socioeconomic status & 0.115 (non-significant) \\
\hline Serum progesterone & 0.000 (Significant) \\
\hline
\end{tabular}

UTI and vaginitis were diagnosed in $10 \%$ and $11 \%$ cases respectively. Systemic illness was elicited on history in $24 \%$ cases, while $6 \%$ patients gave history of suffering from various endocrine disorders. On ultrasound examination missed Miscarriage was found in $8 \%$ inconclusive ultrasound was found in $34 \%$ cases, rest were normal. Of the 38 cases giving history of previous Miscarriage $22 \%$ had previous 1 Miscarriage, previous 2 Miscarriage were seen in $6 \%$ and previous 3 Miscarriages in $8 \%$ patients.

Table 6: Risk factors associated with abortion.

\begin{tabular}{|lll|}
\hline Risk factor & Number & $\begin{array}{l}\text { Percentage } \\
\text { of cases }\end{array}$ \\
\hline $\begin{array}{l}\text { Advanced maternal age }>30 \\
\text { years }\end{array}$ & 9 & 9 \\
\hline $\begin{array}{l}\text { Advanced paternal age }>30 \\
\text { years }\end{array}$ & 35 & 35 \\
\hline H/o contact & 14 & 14 \\
\hline H/o heavy work & 5 & 5 \\
\hline H/o travel & 25 & 25 \\
\hline H/o trauma & 15 & 15 \\
\hline UTI & 10 & 10 \\
\hline Vaginitis & 11 & 11 \\
\hline Previous PTL & 25 & 25 \\
\hline Previous Miscarriage & 38 & 38 \\
\hline $\begin{array}{l}\text { H/o congenital anomaly in } \\
\text { previous pregnancy }\end{array}$ & 7 & 7 \\
\hline Systemic diseases & 24 & 24 \\
\hline Endocrine disorder & 12 & 12 \\
\hline Addictions & 17 & 17 \\
\hline
\end{tabular}

Those having 4 or more Miscarriages comprised only $2 \%$. Most $(36 \%)$ of the patients presented with complaint of bleeding per vaginum. while $30 \%$ had bleeding with pain and $33 \%$ cases had only pain in abdomen. On USG maximum patients $58 \%$ had normal scans. Among these patients the Miscarriage rate was 20.6\%. 34\% of the patients showed inconclusive scan and only $35 \%$ continued with viable pregnancy, rest aborted. About 7 of the 100 cases had preterm labour and 51 cases continued to term.

Rest 42 aborted. H/o contact, travel, trauma, heavy work did not have any statistically proven effect on outcome of pregnancy. Of the 58 cases reaching term 9 landed up in caesarean section, while 44 had normal vaginal delivery. The caesarean rate is $17.6 \%$.

The perinatal outcome in these 58 cases was such that 48 babies were of birth weight $>2.5 \mathrm{~kg}$ and 3 had birth weight $<2.5 \mathrm{~kg}$. Of these 2 were very low birth weight and 4 had IUGR. Serum progesterone varies between 1.5 to 34 .

ROC analysis came up with the cut off of 10.05 with a sensitivity of $93.1 \%$ and specificity of $90.5 \%$. 4(6.8\%) out of 58 viable pregnancies have s. prog. $<10.05$ and 4 $(9.5 \%)$ out of non-viable pregnancies have s. prog. $>10.05$. Mean serum progesterone in viable group is 18.09 and in non-viable group it is 6.707. 
Table 7: Significant previous history.

\begin{tabular}{|c|c|c|c|c|}
\hline Previous history & Continued & Percentage & Aborted & Percentage \\
\hline Preterm labour & 58 & 58 & 42 & 42 \\
\hline Spontaneous abortion & 40 & 76.9 & 12 & 23.1 \\
\hline Abortion & 18 & 47.3 & 20 & 52.6 \\
\hline \multicolumn{5}{|l|}{ Congenital Anomaly } \\
\hline Yes & 1 & 1.7 & 6 & 14.3 \\
\hline No & 57 & 98.3 & 36 & 85.7 \\
\hline \multicolumn{5}{|l|}{ History of contact } \\
\hline Yes & 7 & 12.1 & 7 & 16.7 \\
\hline No & 51 & 87.9 & 35 & 83.3 \\
\hline \multicolumn{5}{|l|}{ History of Travel } \\
\hline Yes & 15 & 25.9 & 10 & 23.8 \\
\hline No & 43 & 74.1 & 32 & 76.2 \\
\hline \multicolumn{5}{|l|}{ History of Trauma } \\
\hline Yes & 6 & 10.3 & 9 & 21.4 \\
\hline No & 52 & 89.7 & 33 & 78.6 \\
\hline \multicolumn{5}{|l|}{ History of Heavy Work } \\
\hline Yes & 4 & 6.9 & 1 & 2.4 \\
\hline No & 54 & 93.1 & 41 & 97.6 \\
\hline \multicolumn{5}{|l|}{ Vaginitis } \\
\hline Yes & 7 & 12.1 & 4 & 9.5 \\
\hline No & 51 & 87.9 & 38 & 90.5 \\
\hline \multicolumn{5}{|l|}{ UTI } \\
\hline Yes & 5 & 8.6 & 5 & 11.9 \\
\hline No & 53 & 91.4 & 37 & 88.1 \\
\hline
\end{tabular}

Table 8: Chief presenting complaints.

\begin{tabular}{|lllll|}
\hline Chief Presenting complaints & Continued & Percentage & Aborted & Percentage \\
\hline Pain & 24 & 72.7 & 9 & 27.2 \\
\hline Bleeding & 25 & 69.5 & 11 & 30.5 \\
\hline Both complaints & 9 & 29 & 22 & 70.9 \\
\hline Total & 58 & & 42 & \\
\hline USG Findings & & & & \\
\hline Normal & 46 & 79.3 & 12 & 20.6 \\
\hline Inconclusive & 12 & 35.2 & 22 & 64.7 \\
\hline Missed & 0 & 0 & 8 & 100 \\
\hline Total & 58 & & 42 & \\
\hline
\end{tabular}

\section{DISCUSSION}

Recent studies suggest that serum progesterone measured in early pregnancy is the most powerful single predictor of pregnancy outcome in natural conceptions (Elson et al, Zainab Ali et al, Phipps et al) The incidence of threatened Miscarriage among first trimester pregnancy cases presenting to Gynaecology O.P.D was $8.8 \%$ in my study. Threatened Miscarriage is very common in the first trimester; about 25-30\% of all pregnancies have some bleeding during the pregnancy. Less than one half proceed to a complete Miscarriage. The overall miscarriage rate is reported as $15-20 \%$. About $80 \%$ of miscarriages occur within the first trimester. Miscarriage, also known as spontaneous abortion and pregnancy loss, is the natural death of an embryo or fetus before it is able to survive independently. ${ }^{2}$ Miscarriage, also known as spontaneous abortion and pregnancy loss, is the natural death of an embryo or fetus before it is able to survive independently. As per Table 2 represents effect of demographic profile on Pregnancy. However, with maternal age distribution with 37,44 and 10 cases of threatened miscarriage between the age group of 26-30 years, 21-25 years and less than 20 years of age respectively. Authors had 9 cases of more than 30 years who were form high risk group, as with advancing age the oocyte quality decreases, risk of congenital malformation increases, and chances of successful pregnancy decrease. According to distribution of cases according to their husband's age. 25 patients reported their husband's age to be less than 25 years while 40 and 
35 cases had paternal age in the range of 26-30 years and between 31-35 years respectively. However, among primiparous $76.9 \%$ of pregnancies continued and about $52.6 \%$ cases aborted in cases of multiparous pregnancy.

In Tables 3,4 and 5, The mean age of the studied population was $25.7 \pm 4.35$ years, the mean gestational age at progesterone assay was $9.7 \pm 0.5$ week and women were tested for serum progesterone and USG and followed up to term. Women included in this study were classified according to the viability of their pregnancies into; viable pregnancy group 58 cases $(58 \%)$ and non-viable pregnancy group (ended by miscarriages) 42 cases (42\%).

The mean serum progesterone of the studied population was significantly high in viable pregnancy group $(18.09 \pm 5.9 \mathrm{ng} / \mathrm{ml})$ compared to non-viable pregnancy group $(6.707 \pm 3.02 \mathrm{ng} / \mathrm{ml})$. The relations between serum progesterone and maternal age or gestational age of the studied population were statistically insignificant; also, the relation between serum progesterone and past history of early miscarriage was statistically insignificant. The ROC curve analysis demonstrated a significant ability of serum progesterone to differentiate between viable and nonviable pregnancies.

The area under curve (AUC) for progesterone was 0.971 (95\% CI, 0.944-0.997) with the parameters calculated from the ROC curve shown in Figure 1. In this study; $6.8 \%$ of viable pregnancies had serum progesterone level $<10.05 \mathrm{ng} / \mathrm{ml}$, while $9.5 \%$ of non-viable pregnancies had serum progesterone level $>10.05 \mathrm{ng} / \mathrm{ml}$, the serum progesterone at cut off level $10.05 \mathrm{ng} / \mathrm{ml}$ was $93.1 \%$ sensitive to diagnose non-viable pregnancy and was $90.5 \%$ specific to diagnose viable pregnancy. Below is table showing various study and their reference progesterone values with sensitivity and specificity.

As signified in Table 6, History of contact a was found in 14 cases out of which 7 aborted and with History of travel and history of trauma was seen in 25 cases and 15 cases out of which 10 and 9 cases aborted respectively. History of heavy work was noticed in 5 cases of which 1 aborted. None of the factors were found significant. ( $P$ value $>0.05$ ). History of vaginitis and UTI was positive in 11 and 10 cases respectively but both were not significantly associated. ( $\mathrm{P}$ value $>0.05$ ).

The most common risk factor among present cases was a history of previous Miscarriages. 38\% cases had a history of previous miscarriage. This indicates that previous pregnancy loss is an important risk factor for $1^{\text {st }}$ trimester miscarriage.

One percent of cases aborted for recurrent causes and $17 \%$ for non-recurrent causes in subsequent pregnancy. Table 9 represents associated systemic diseases, out of which it was found that nearly 6 cases of PCOS aborted and none continued, and Rest 10 cases were not significantly associated with viability.
Table 9: Associated systemic diseases.

\begin{tabular}{|lll|}
\hline Systemic diseases & Continued & Aborted \\
\hline Asthma & 3 & 1 \\
\hline Epilepsy & 4 & 2 \\
\hline Gastroenteritis & 2 & 1 \\
\hline Hyperemesis & 4 & 2 \\
\hline Koch's & 3 & 0 \\
\hline Hydronephrosis & 0 & 1 \\
\hline RHD & 0 & 1 \\
\hline None & 42 & 34 \\
\hline DM & 1 & 1 \\
\hline Hypothyroid & 3 & 1 \\
\hline PCOS & 0 & 6 \\
\hline Total & 62 & 50 \\
\hline
\end{tabular}

In Table 7 showing History of spontaneous pregnancy loss that 22,6,8 and 2 women were associated with previous 1,2,3 and 4 pregnancy losses respectively. There were 62 cases of no previous history of Miscarriage. Thus, majority of women had no previous pregnancy losses. Recurrent miscarriage, defined as the loss of three or more consecutive pregnancies, affects $1 \%$ of couples trying to conceive, as per Stirrat G M. ${ }^{17}$

According to a study by Regan $\mathrm{L}$ et al, the risk of a further miscarriage increases after each successive pregnancy loss, reaching approximately $40 \%$ after three consecutive pregnancy losses, and the prognosis worsens with increasing maternal age. ${ }^{18}$

As shown in Table 8 , The most common symptom of a miscarriage is bleeding. ${ }^{19} 36 \%$ of the cases presented with bleeding PV and $33 \%$ of patients presented. However, both symptoms were present in $31 \%$ cases. According to a study of women who seek clinical treatment for bleeding during pregnancy, about half will go on to have a miscarriage. ${ }^{19}$

Table 10: Pregnancy outcome.

\begin{tabular}{|ll|}
\hline Pregnancy Outcome & Continued \\
\hline Term & 51 \\
\hline Preterm & 7 \\
\hline Normal & 49 \\
\hline VLBW & 2 \\
\hline LBW & 3 \\
\hline IUGR & 4 \\
\hline Normal Labour & 44 \\
\hline LSCS & 9 \\
\hline PTL & 5 \\
\hline
\end{tabular}

As per USG findings, $58 \%$ cases showed a normal scan out of which about $79 \%$ normal scans continued as viable pregnancy while about $20 \%$ aborted. It was inconclusive in $34 \%$ cases were having inconclusive USG findings requiring follow up USG after 1 week and $8 \%$ cases were diagnosed as missed miscarriage. 
The percentage of Miscarriage was reduced with normal scans in my study. Most prospective series report a loss rate of $3.4-5.5 \%$ if bleeding occurs after fetal heart activity starts, and identification of fetal heart activity by ultrasound in primary healthcare settings carries $97 \%$ likelihood for the pregnancy continuing beyond 20 weeks. $^{20}$

Table 10 showing the pregnancy outcome of which 42 aborted, 7 cases ended as preterm labour and 51 pregnancies reached up to term. Thus, the overall Miscarriage rate of present study was $42 \%$.

The cut off level of serum progesterone in the present study was $10.05 \mathrm{ng} / \mathrm{ml}$ and the sensitivity and specificity for the test was $93.1 \%$ and $90.5 \%$ respectively.

Funding: No funding sources

Conflict of interest: None declared

Ethical approval: The study was approved by the Institutional Ethics Committee

\section{REFERENCES}

1. Hasan R, Baird DD, Herring AH, et al. Patterns and predictors of vaginal bleeding in the first trimester of pregnancy. Ann Epidemiol. 2010;20(7):524-31.

2. Everett $\mathrm{C}$. Incidence and outcome of bleeding before the 20th week of pregnancy: prospective study from general practice. BMJ. 1997;315(7099):32-4.

3. Blohm F, Friden B, Milsom I. A prospective longitudinal population-based study of clinical miscarriage in an urban Swedish population. BJOG. 2008;115(2):176-83

4. Hemminki E. Treatment of miscarriage: current practice and rationale. Obstet Gynecol. 1998; 91(2):247-53.

5. Elson J, Salim R, Tailor A, Banerjee S, Zosmer N, Jurkovic D. Prediction of early pregnancy viability in the absence of an ultrasonically detectable embryo. Ultrasound Obstet Gynecol. 2003; 21(1):57-61.

6. Brar AK, Frank GR, Kessler CA, Cedars MI, Handwerger S. Progesterone-dependent decidualization of the human endometrium is mediated by cAMP. Endo. 1997;6(2):301-7.

7. Hanita O, Hanisah AH. Potential use of single measurement of serum progesterone in detecting early pregnancy failure. Malaysian J Pathol. 2012;34 (1):41-6.

8. al-Sebai MA, Kingsland CR, Diver M, Hipkin L, McFadyen IR. The role of a single progesterone measurement in the diagnosis of early pregnancy failure and the prognosis of fetal viability. $\mathrm{Br} \mathrm{J}$ Obstet Gynecol. 1995; 102(5):364-9.

9. Phipps MG, Hogan JW, Peipert JF, LambertMesserlian GM, Canick JA, Seifer DB. Progesterone, inhibin and hCG multiple marker strategy to differentiate viable from nonviable pregnancies. Obstet Gynecol 2000; 95(2): 227-31.

10. Carson SA, Buster JE. Ectopic pregnancy. N Engl J Med. 1993; 329(16):1174-81.

11. Taghavi AH. Detection of changes of hCG, progesterone and estradiol serum levels in threatened Miscarriage in the first three months of gestation. Iran J Endocrinol Metab. 2004;6(2):163-9.

12. Midha U, Narang APS, Sofat IB, Avasthi K, Jain M. Serum progesterone levels in Miscarriages. J Obstet Gynecol India. 2002;52:47-50.

13. Vicdan K, Zeki Isik A (2001) Luteal phase hormonal profile in prediction of pregnancy outcome after assisted reproduction. Eur J Obstet Gynecol Reprod Biol. 96(1):98-101

14. Al Jufairi ZA. The value of serum progesterone measurement in early pregnancy. Bahrain Medical Bulletin. 2000;22(1):18-20.

15. The Johns Hopkins Manual of Gynecology and Obstetrics. $4^{\text {th }}$ ed. Lippincott Williams and Wilkins; 2012: 438-439. ISBN 9781451148015.

16. "What is pregnancy loss/miscarriage?". Available at: www.nichd.nih.gov/.

17. Stirrat GM. Recurrent miscarriage I: definition and epidemiology. The Lancet. 1990;336(8716):673-5.

18. Regan L,Braude PR,Trembath PL. Influence of past reproductive performance on risk of spontaneous Miscarriage. BMJ 1989;299(6698):541-5.

19. Gracia C, Sammel M, Chittams J, Hummel A, Shaunik A, Barnhart K. "Risk factors for spontaneous Miscarriage in early symptomatic firsttrimester pregnancies". Obstet Gynecol. 2005 106(51):993-9

20. T, Srisomboon J, Wanapirak C, Sirichotiyakul S, Pongsatha S, Polsrisuthikul T. Pregnancy outcome of threatened Miscarriage with demonstrable fetal cardiac activity: a cohort study. J Obstet Gynaecol1995;21(4):331-5.

Cite this article as: Dave A, Patil R, Bansal P, Malhotra A. Role of serum progesterone in threatened miscarriage. Int J Reprod Contracept Obstet Gynecol 2018;7:4272-8. 